\title{
Russia's food security: obstacles to development
}

\author{
Dmitri Loginov ${ }^{1 *}$ \\ ${ }^{1}$ Federal State Budgetary Educational Institution of Higher Education «Vyatka State University» \\ (FSBEI HE «VyatSU»), 610000, 36, Moskovskya street, Kirov, Russia,
}

\begin{abstract}
Since 2010, the Russian Federation has developed a practice of adopting and implementing the food security doctrine. The adoption of this normative legal act allowed us to establish a clear framework for the country's food security criteria, and to specify the risks and threats to national food security. The adoption of a new version of the Russian food security doctrine in 2020 makes it possible to more purposefully influence potential threats to the country's food security and solve a wider range of tasks for ensuring Russia's food security in a comprehensive manner
\end{abstract}

\section{Introduction}

Food security is an important and special aspect of national security. The role of food security in shaping the nation's security is determined by the fact that food security of the population is the Foundation of human well-being and strongly affects the citizen's assessment of the quality of life in his country. At the same time, ensuring the country's food security is not a trivial task. The movement towards food security should be based on a clear system of criteria. Only then can we achieve clear results in ensuring food security. Currently, Russia's food security is not fully secured. The degree to which the nation's food security has been achieved is relative. It depends on many factors and circumstances. First of all, it depends on what is considered as a criterion of the presence of the state of protection of society from threats of loss of the state of food security. In this regard, the study of ways to ensure food security in Russia is an urgent scientific and practical problem.

Ensuring food security during the economic crisis is particularly important. One of the components of food security is the efficiency of the food industry. The food industry also plays an important role in import substitution. The restriction of food supplies to Russia has become a stimulating factor for the domestic food industry. This led to an increase in selfsufficiency of the Russian population with food products. In addition, there is a unique opportunity to increase food exports. Today, Russia has a two-fold situation where some types of food have reached a state of self-sufficiency, while others remain importdependent. However, not every region of Russia relies on the food industry for economic development. This increases the uneven socio-economic development of certain regions of Russia. At the same time, it is advisable to focus on stimulating import substitution

${ }^{*}$ Corresponding author: +7-912-727-11-10 doctorloginov@mail.ru 
processes in the food market in those regions where the indicators of self-sufficiency in food are below average. In some regions of Russia, there is still an incomplete load of production capacity of food industry enterprises. In addition, the processes of innovative development in the food industry have not reached the necessary pace, that is, the food industry remains insufficiently innovative [1].

One of the priority tasks of the state is to provide the population with food in accordance with the conditions of physical and economic accessibility, as well as of appropriate quality [2].

Food security has now become an international challenge. Many countries around the world interpret the task of ensuring food security in terms of reducing the number of hungry people. This approach and implemented practical actions have yielded results: the number of hungry people in the world is gradually decreasing, and we can talk about the dynamics of reducing the number of hungry people from 1 billion to 850 million [3].

On January 30, 2010, the Russian food security Doctrine was approved by presidential decree number 120. This act was an important turning point in the development of Russian food security. It was with the adoption of this doctrine that the state's work to ensure food security became systematic and was supported by quantitative indicators [4].

The adopted doctrine defined food security as a state of the country's economy that ensures food independence, as well as physical and economic accessibility of food to the population. At the same time, food must meet the quality requirements established by the state and must ensure that the population can lead a healthy and active lifestyle [5].

Thus, we can conclude that the developers of the Russian food security Doctrine have established three important criteria for food security: 1) physical availability of food; 2) economic availability of food; 3 ) environmental safety of food [6, 7].

Special importance is attached to the food industry in ensuring food security. The special role of the food industry in ensuring food security is due to the fact that it supplies the population with ready-to-eat food, and therefore is subject to the most careful and careful assessment. In addition, the choice of raw materials by food industry enterprises largely depends on the volume of agricultural imports into the country [8].

The food industry can be attributed to the leading force of the agro-industrial complex, which ensures the progress of the related sectors of the economy, especially agriculture. In a sense, the food industry can be seen as a driver of the region's economic growth.

Currently, many scientists have begun to consider the problem of food security through the prism of the effectiveness of the food industry. Among the foreign experts who study this issue, it is worth mentioning U. Life, M. Tracy, T. Malthus and E. Reinert, who formed the theoretical and methodological foundation for the study of food security [9-13].

Domestic research on the role of the food industry in the formation of food security carried out by O. V. Borisov, D. V. Goncharov, S. V. Kataev, A. S. Nutsubidze, A. E. Akhmedov, M. Shatalov, A. A. Gladysheva, A. Ratnikova, V. V. Orlov, Yu. a. Klokov V., V. A. Dotsenko, E. J. Righteous and others [14-19].

For this study, the works of such Russian experts in the field of food security as A. N. Chekavinsky, M. F. Tyapkin, N. A. Antipyev and others are significant [2, 20].

It is important to take into account that the food industry has a complex structure, it includes more than 30 industries.

It is important for the state to give the food industry an impetus for innovative development. This is particularly significant given the high potential of the food industry as a multiplier for the development of the regional economy.

Moreover, the state's efforts to strengthen food security cannot be limited to the limits of food security for the population. The agro-industrial complex as a whole is a strong driver of economic growth. With a successful selection of impact factors, the effect of 
strengthening food security can extend to other components of national security, primarily social, industrial, scientific, technical, and economic security [21, 22].

\section{Analysis of the state and dynamics of food security in Russia}

In the course of the research, methods such as comparison of legal acts and dynamic analysis of statistical data were mainly used.

It is important to compare the food security Doctrine of Russia, which was in force from 2010 to 2020, with the food security Doctrine, which came into effect in 2020.

According to the food security Doctrine of Russia, approved in 2010, food security of the Russian Federation is a state of the country's economy that ensures food independence of the Russian Federation, guarantees physical and economic accessibility for each citizen of the country of food products that meet the requirements of the legislation of the Russian Federation on technical regulation, in volumes not less than the rational norms of food consumption necessary for an active and healthy lifestyle.

The new version of the Russian food security Doctrine, while maintaining the established approach, contains some differences from the previous formulation of food security. In particular, food security in the new version of the Doctrine refers to the state of social and economic development of the country, which ensures the food independence of the Russian Federation, guarantees physical and economic accessibility for each citizen of the country of food products that meet the mandatory requirements, in volumes not less than the rational norms of consumption of food products necessary for an active and healthy lifestyle.

What is the novelty of the updated version of the definition of food security? If earlier food security was understood as the state of the country's economy, now it is the state of social and economic development. This means that the essence of food security now extends to a wider range of phenomena. This is not just the state of the economy. This is the state of society as well. In addition, this is a dynamic phenomenon, since food security now belongs to the processes of socio-economic development. Indeed, the essence of food security is more evident in the course of monitoring changes in society, including the development of the level and quality of life.

The view on the criteria that food products must meet has also changed. If earlier it was only the requirements of national legislation on technical regulation, now we have taken a broader formulation - all mandatory requirements for products. It can be assumed that these may be not only requirements established by legal acts, but also requirements put forward by public organizations, as well as standards set by individual enterprises. Thus, the view of food quality standards in the new food security Doctrine has become much broader.

In addition to the differences in the definition of food security that were fixed by the previously existing and newly approved food security doctrines, it is important to emphasize certain constants, that is, those provisions that have not been questioned or revised during the ten years of implementation of the Russian food security Doctrine. This is, first of all, a look at the structure of food security. Invariably, there are three mandatory components of food security: food independence of the country; physical availability of food; economic accessibility of food. Equally important is the criterion of minimum per capita food consumption. It was decided to maintain the same approach-compliance with rational consumption standards that ensure an active and healthy lifestyle.

I want to focus in a special way on the indicated constants.

First, the structure of food security. For Russia, it is no accident that food independence is placed first in the structure of food security. After all, maintaining the country's independence in providing the population with food is one of the most important conditions 
for preserving national sovereignty, as well as ensuring good export opportunities for the domestic agro-industrial complex.

Secondly, the thesis about the mandatory physical availability of food has not lost its relevance. Indeed, the lack of food within physical reach is one of the criteria for a humanitarian disaster. The population should have no difficulty in physically purchasing food.

Third, the economic availability of food is an important criterion for well-being. This third component, as the experience of ten years of implementing the food security Doctrine has shown, is not easy to achieve. Russians are still not equal in their ability to buy food. The criterion of being able to purchase sufficient food in all social strata of the population has not yet been reached. It should be noted that there is still a layer of people who are experiencing restrictions in their ability to purchase food.

It is necessary to pay attention to one important methodological feature of the new version of the Russian food security Doctrine. If the previous version stated the goals and objectives of the Doctrine at the very beginning of its text, the current version allocates a separate Chapter to the goals and objectives of the Doctrine.

In particular, the previous version of the Doctrine States that the purpose of this document is to provide the country's population with safe agricultural products, fish and other products from aquatic biological resources (hereinafter - fish products) and food. The guarantee of its achievement is the stability of domestic production, as well as the availability of necessary reserves and reserves.

The new version of the Doctrine indicates that its strategic goal is to provide the country's population with safe, high-quality and affordable agricultural products, raw materials and food in volumes that ensure rational norms of food consumption.

There is a methodological progress in looking at the strategic goal of the food security Doctrine. If ten years ago it was aimed at providing the population with safe food, now, along with safety, its properties such as quality and availability are indicated. As can be seen, views on the goals of the Doctrine have undergone an evolution of complexity. Safe food is a basic condition for food security, and high-quality food demonstrates the level of development of technologies and care not only for preserving the health of the population, but also for increasing it. If we talk about accessibility, which is emphasized in the new version of the Doctrine, we can confidently state the increase in the humanitarian and social orientation of the document under consideration. Indeed, food should be available to all, not just to a certain part of society.

Of particular interest is the evolution of the objectives of the food security Doctrine. If the old version of the doctrine identified four tasks, the new One has thirteen.

Initially, the tasks of the Doctrine were distributed in such areas as forecasting threats, ensuring food independence, ensuring the availability of food and ensuring food security.

The new version of the Doctrine revised the priorities. On the first place among the tasks left to ensure food independence. At the same time, the process of ensuring food independence will now be supported by a resource such as the principles of science-based planning. This means that the work to achieve food independence of the country will enter into the course of purposeful, thoughtful and comprehensive planning, will acquire a progressive, systematic character.

The issue of forecasting threats to food security is not ignored by the new food security Doctrine, but only moved from the first to the second most important place. At the same time, the role of the process of forming food stocks is traditionally emphasized.

At the same time, the issue of ensuring the physical and economic accessibility of food is considered in the new version of the Doctrine more concisely. If earlier the possibility to lead an active and healthy lifestyle was considered as a criterion of accessibility, then this criterion fell out of the modern version of the tasks of the Doctrine, instead of which such a 
criterion as a healthy diet is designated. To some extent, the concept of a healthy diet replaces the concept of a diet that provides an active and healthy lifestyle. However, the refusal to appeal to an active lifestyle is a cause for concern. After all, it is active life activity that provides a person with both maximum productivity in work and maximum longevity. From our point of view, the criterion of an active lifestyle should be given great attention in the philosophy of the food security Doctrine.

It is important to emphasize that the new nine objectives of the food security Doctrine are identified in a very timely manner and allow a much broader view of the scope of this document, and therefore make it more applicable. Particular importance is attached to such areas of implementation of the objectives of the Doctrine as strengthening the export positions of our country, the development of agricultural science, the infrastructure of the agro-industrial complex and the training system for agricultural production. All this suggests that the Doctrine of food security in its current form applies to all areas of state regulation of agricultural production and can be considered a universal guide to the formation of strategies and tactics of state agricultural policy for the long term.

One of the main aspects of the novelty of the Russian food security Doctrine adopted in 2020 was a new look at the essence of food independence.

In 2010, Russia's food independence was defined as sustainable domestic food production in volumes not less than the established threshold values of its share in the commodity resources of the domestic market of the corresponding products. Based on this definition, we can conclude that initially food independence was considered as a relative compromise between domestic production and imports in the domestic food market of Russia. At the same time, the system of threshold values of the share of domestic production in the commodity resources of the main types of food was considered as a criterion for a satisfactory state of food independence.

The current view of Russia's national food independence, approved in January 2020, is fundamentally different from the previous one. Now Russia's food independence is understood as self-sufficiency of the country with the main types of domestic agricultural products, raw materials and food. Thus, we can distinguish two fundamentally new circumstances in the interpretation of food independence.

First, food independence is no longer seen as a compromise between domestic production and food imports, but as a state of self-sufficiency in the country's food needs. In other words, the requirements for recognizing the country's food independence as satisfactory have become more stringent.

Secondly, now the requirement of food independence applies not only to the food market, but also to the market of agricultural products, raw materials and food. This means that in order to achieve food independence, it is not enough to provide the food market with ready-made food products produced on the territory of Russia. It is necessary that the raw materials for them should also be produced in the domestic space. This approach puts Russian agricultural producers in a more protected position. In addition, the criterion of food independence can now be extended beyond food products. After all, the composition of agricultural products and agricultural raw materials includes not only products used for the production of food products, but also technical agricultural raw materials, such as raw materials for the textile, chemical, pharmaceutical industry and other industrial productions of non-food profile.

It is interesting that the view of the updated food security Doctrine of Russia on the essence of rational norms of food consumption remained unchanged. As before, this concept is interpreted as a diet, presented in the form of a set of products, including food products in volumes and ratios that meet modern scientific principles of optimal nutrition, taking into account the existing structure and traditions of nutrition of the majority of the population. 
In the opinion of the author of the article, it would be rational to detail the reference to the essence of modern scientific principles of optimal nutrition in the framework of the considered definition, due to the fact that scientific views on nutrition are very different, and in the proposed context it is difficult to determine which principles of optimal nutrition are recommended to rely on. Obviously, it is necessary to clarify the concept of optimal nutrition in terms of its impact on the preservation of human health and longevity and on the possibility of its most complete development. The reference in this definition to the established structure and traditions of nutrition of the majority of the population is also debatable. The fact is that tradition often contradicts the latest knowledge. In this case, it is not clear what to consider as a priority, the latest knowledge about the principles of nutrition obtained by science, or tradition? Moreover, the current nutritional structure of the majority of the population may be forced, rather than consciously chosen. The forced nature of the current food structure may be due to insufficient economic availability of certain most valuable food products, as well as insufficient dissemination of the latest scientific knowledge about optimal nutrition among the population.

The most important quantitative characteristic of the food security Doctrine is the system of threshold values for indicators of food independence. The process of updating the Doctrine covered both the composition of indicators and their thresholds. Thus, instead of the previously existing system consisting of eight indicators of food independence, a system of eleven indicators was approved. New indicators were: vegetables and melons; fruits and berries; seeds of the main agricultural crops of domestic selection. All previously used indicators of food independence are preserved.

The considered evolution of the system of indicators of food independence is quite justified. Indeed, vegetables, melons, fruits and berries are very important elements of optimal nutrition, corresponding to modern scientific ideas about nutrition. These foods are rich in fiber - one of the most important factors of a healthy human diet. Therefore, it is quite reasonable to set threshold values for indicators of self-sufficiency of the Russian food market with these food products. As for the regulation of the minimum supply of the Russian market with seeds of domestic selection, this decision can be considered very correct, since it is aimed at improving the entire chain of creating food products, in particular, at its most initial links - the production of seeds to ensure commercial crops.

As for the quantitative characteristics of the threshold values of indicators of food independence of Russia, it is important to note that in the new version of the food security Doctrine, no reduction of the threshold value was allowed for any of the indicators. In fact, for some indicators, the threshold values remained at the same levels, while for others they were raised. Preservation of the previous level of the threshold value is noted for such types of food as grain, meat and meat products, milk and dairy products, potatoes, food salt.

The minimum threshold level of the indicator in this group of food types is 85 percent. It should be noted that in the author's opinion, the level of threshold values for some of the considered indicators could be increased. This may apply to meat and meat products, milk and dairy products, and food salt. In particular, in the future, we should focus on increasing the threshold values by five percentage points for indicators such as meat and meat products (from 85 to 90 percent), milk and dairy products (from 90 to 95 percent), and salt (from 85 to 90 percent).

The threshold values for food independence indicators for grains and potatoes are currently set at the justified level of 95 percent. Further increase of these indicators is impractical, since the actual availability of grain and potatoes in a particular calendar year depends to a large extent on the prevailing weather conditions. In this case, if the threshold level of the indicator is more strictly selected, the lean years will unreasonably distort the picture of the current food security. 
The new version of the food security Doctrine tightened the requirements for recognizing the state of food independence as satisfactory for indicators such as sugar, vegetable oil, fish and fish products. At the same time, the threshold values for sugar and vegetable oil increased immediately by ten percentage points, from 80 to 90 percent, for fish and fish products - by five percentage points, from 80 to 85 percent. As you can see, the country's leadership began to impose stricter requirements for self-sufficiency of the national market with sugar and vegetable oil, as well as fish and fish products. I would especially like to emphasize the need to further tighten the requirements for self-sufficiency of the country with fish and fish products due to the fact that fish is one of the most important elements of a healthy diet, which is extremely necessary for the Russian population.

The implementation of the food security Doctrine is closely linked to the task of reducing poverty in the country. Indeed, the higher the economic availability of food, the smaller the number of poor in society. From this point of view, it is interesting to analyze the dynamics of the population with monetary incomes below the subsistence minimum for the period of the Russian food security Doctrine.

As can be seen from table 1, the dynamics of changes in the level of poverty in Russia during the implementation of the food security Doctrine was not so significant. We can say that the Doctrine was implemented in difficult social conditions, accompanied by the implementation of a number of economic shocks. Of course, this could not have a positive impact on the level of economic availability of food in the country.

Table 1. The number of people with monetary incomes below the subsistence level in the Russian Federation, as a percentage of the total population.

\begin{tabular}{|c|c|c|c|c|c|c|c|c|c|c|}
\hline Year & 2009 & 2010 & 2011 & 2012 & 2013 & 2014 & 2015 & 2016 & 2017 & 2018 \\
\hline $\begin{array}{c}\text { Value of } \\
\text { indicator }\end{array}$ & 13.0 & 12.5 & 12.7 & 10.7 & 10.8 & 11.3 & 13.4 & 13.2 & 12.9 & 12.6 \\
\hline
\end{tabular}

Table 1 suggests the role of the food security Doctrine in addressing poverty. The fact is that increasing the level of economic availability of food in market conditions is most preferable along the path of saturation of competition. The more competition there is in the market, the more likely it is to reduce the equilibrium consumer prices, which ultimately leads to the consumer winning. Thus, stimulating food production ultimately contributes to increasing the level of its economic accessibility.

A more optimistic picture is shown by the indicator of the share of employees of organizations with accrued wages below the subsistence level of the working-age population in the Russian Federation (table 2). Over the period of 2009-2019, this indicator was not stable. However, there has been a marked decrease in the share of workers whose wages are below the subsistence level.

Table 2. The share of employees of organizations with accrued wages is lower than the subsistence level of the working-age population in the Russian Federation, \%.

\begin{tabular}{|c|c|c|c|c|c|c|}
\hline Year & 2009 & 2011 & 2013 & 2015 & 2017 & 2019 \\
\hline Value of indicator & 10.4 & 13.1 & 7.8 & 10.7 & 7.3 & 3.3 \\
\hline
\end{tabular}

The decrease in the share of workers whose work is paid below the subsistence level indicates a change in the very nature of poverty. Within the analyzed period, poverty has largely ceased to be the lot of workers. It can be assumed that by now, poverty is more related to factors of social disadvantage than to the factor of low wages. This feature of 
modern poverty indicates that measures to help citizens who need better nutrition should be focused on those segments of the population that are exposed to the maximum social risks. This conclusion can be fully extended to measures to increase the economic availability of food targeted at the poor.

Important role in the analysis of the conditions for the realization of food security Doctrine plays a dynamic evaluation of the assets ratio, calculated as the ratio of money incomes of $10 \%$ most and $10 \%$ least well-off population. There was no significant improvement in this indicator for the period 2010-2018 (table 3).

Table 3. Fund ratio (the ratio of cash income of $10 \%$ of the most and $10 \%$ of the least affluent population) in the Russian Federation.

\begin{tabular}{|c|c|c|c|c|c|c|c|c|c|c|}
\hline Year & 2009 & 2010 & 2011 & 2012 & 2013 & 2014 & 2015 & 2016 & 2017 & 2018 \\
\hline $\begin{array}{c}\text { Value of } \\
\text { indicator }\end{array}$ & 16.6 & 16.6 & 16.2 & 16.4 & 16.1 & 15.8 & 15.5 & 15.5 & 15.4 & 15.6 \\
\hline
\end{tabular}

It should be borne in mind that if the ratio of funds decreases and, consequently, the level of material well-being of the population is equalized, the situation on the food market will systematically improve. This is due to the fact that it is the lower-income segments of the population that are most sensitive to improving their financial situation by increasing food consumption. The upper income strata of the population are mostly quite satisfied with the level of their nutrition and spend the increase in their income on the acquisition of values that are minimally related to food. Thus, it would be appropriate to make efforts to equalize the social stratification of the population, including the goal of increasing demand in the food market.

The final result of the measures taken by the Government of the Russian Federation to implement the food security Doctrine is a reduction in the share of imports in national food resources. An assessment of the corresponding indicator for the period 2009-2019 (based on the results of the third quarter of each year) allowed us to conclude that the share of imports in Russian food resources has indeed significantly decreased (table 4).

Table 4. Share of imported food products in the commodity resources of retail food trade in the Russian Federation, in the third quarter of the corresponding year, \%.

\begin{tabular}{|c|c|c|c|c|c|c|c|c|c|c|c|}
\hline Year & 2009 & 2010 & 2011 & 2012 & 2013 & 2014 & 2015 & 2016 & 2017 & 2018 & 2019 \\
\hline $\begin{array}{c}\text { Value of } \\
\text { indicator }\end{array}$ & 34 & 33 & 30 & 34 & 35 & 32 & 27 & 22 & 22 & 22 & 24 \\
\hline
\end{tabular}

Thus, in 2009, prior to the entry into force of the Russian food security Doctrine, imports were present in the national food resources by 34 percent, which can be estimated as a significant and very noticeable share. Moreover, this situation cannot be described as acceptable, since Russia has sufficient resources for food production (primarily land resources), with the exception of climatic conditions for growing certain tropical fruits.

The presence of imports in domestic food resources by 34 percent can be considered a threat to food security, since this fact indicates that a third of all Russian food expenditures were spent in the considered time period to pay for products produced abroad.

Since 2010, a slow process of reducing the share of imports in Russian food resources has begun. Thus, in the third quarter of 2010, the analyzed indicator decreased by one percentage point compared to the corresponding period in 2009. A more noticeable decline, by three percentage points, was marked by 2011. However, in 2012-2013, the analyzed indicator began to increase again, which may have been due to Russia's accession to the world trade organization in August 2012. 
The trend finally unfolded in 2014, which, it should be noted, coincided with the sanctions conflict between a number of Western countries and Russia. In the third quarter of 2014, only 32 percent of Russian food resources were available, and in the corresponding period of 2015, the level of this indicator fell to 27 percent. The 2016-2018 period was characterized by a steady 22 percent retention rate, and in the third quarter of 2019 (the last available period for analysis), an increase of two percentage points was recorded.

Describing the overall situation of filling Russian food resources with imports, we can state that this indicator has not yet reached its optimal value. According to the author of the article, it would be justified to take further regulatory measures that would reduce the share of imports in food resources to 10-15 percent. It is in this situation that we can expect to achieve an optimal balance between supply and demand in the Russian food market, when the absolute majority of the costs of food demand sub-budgets are carried out in favor of domestic producers. This situation is justified from the point of view of creating optimal conditions for investment in the Russian agro-industrial complex and for the most profitable reproduction of capital in the agriculture and food industry of Russia.

\section{Conclusion}

Food security threats remain in the Russian Federation. The main task in terms of ensuring national food security is to prevent possible threats and reduce the risks that accompany the existing set of threats.

One of the main threats to Russia's food security is the loss of food independence. Since the 1990s, Russia has been in difficult conditions to ensure food independence, which is associated with fairly free access of imported food resources in the initial period of market reforms, when the domestic agro-industrial complex was still too weak to ensure its competitiveness.

In the current circumstances, the development and adoption of the Russian food security Doctrine in 2010 was completely justified. In the first ten years of implementation, the application of the food security Doctrine has produced tangible positive results. First of all, this is a decrease in the share of imports in Russian food resources.

Nevertheless, the potential for further increasing Russia's food independence remains. This requires a system of measures to further strengthen Russia's self-sufficiency in food. The share of imports in domestic food resources should continue to decline.

One of the significant limitations in the further development of Russia's food security is the problem of poverty. Low-income social strata are limited in their ability to purchase food for their full needs, and therefore they have little access to active and healthy lifestyles. Thus, the further policy of developing food security in Russia is proposed to focus on providing targeted targeted support to low-income segments of the population in the form of preferential access to food.

The adoption of the new version of the food security Doctrine in 2020 is justified. The new version of the Doctrine tightened the criteria for recognizing the fact of food independence of the country to the level of self-sufficiency in food, expanded the range of indicators of food security, increased the requirements for the threshold values of most of them, and diversified the range of measures to ensure food security.

It is recommended that in the next decade of implementing the Russian food security Doctrine, efforts should be focused on improving the competitiveness of the Russian agroindustrial complex, taking into account that in the long term, its subjects will probably face very tough challenges from international competition in the food sector. 


\section{References}

1. V. Glinskiy, L. Serga, M. Alekseev, N. Samotoy, E. Simonova, ME Procedia 15th Global Conference on Sustainable Manufacturing 21, 838-845 (2018)

2. A.N. Chekavinskiy, R.Yu. Selimenkov, Economic and social changes: facts, trends, forecast, 4(34), 226-235 (2014)

3. Expert.ru

4. The Doctrine of Food Security of the Russian Federation: Decree of the President of the Russian Federation of 30 January 2010, No. 120

5. A.S. Natsubidze, Postcrisis development of the food industry in Russia: threats, opportunities, prospects (MIGCU, Moscow, 2013)

6. The concept of long-term socio-economic development of the Russian Federation for the period up to 2020: Decree of the Government of the Russian Federation of 17 November 2008 N 1662-r.

7. The fundamentals of the state policy of the Russian Federation in the field of healthy nutrition for the population until 2020: the order of the Government of the Russian Federation of 25 October 2010 No. 1873-r.

8. A.A. Gladysheva, T.A. Ratnikova, Economic Journal Of The Hse 2 (2014)

9. T. Buccellato, F. Santangelo, Foreign Direct Investments Distribution in the Russian Federation: Do Spatial Effects Matter? (2009)

10. M. Tracy, Agriculture and Food in the Economy of Developed Countries: An Introduction to Theory, Practice, and Politics (1995)

11. The State of Food Insecurity in the World. FAO, IFAD, WFP (2015). http://www.fao.org/3/ai4646e.pdf

12. W. Liefert, Comparative advantage in Russian Agriculture, Agriculture Economics 84(3), $762-767$ (2002)

13. D. Shields, Farm Safety Net Programs: Background and Issues, Congressional Research Service Report,August 21 (2015).

http://www.fas.org/sgp/crs/misc/R43758.pdf

14. A.E. Akhmedov, M.A. Shatalov, Formation of the mechanism for managing the integration development of food industry enterprises in the current conditions of management (Voronezh. Econ.-Legal Ins-t. Voronezh, 2013)

15. O.V. Borisova, Food industry as a factor of sustainable development of rural areas, Nikonov readings 11, 263-265 (2006)

16. V.D. Goncharov, Food industry in the system of ensuring food security of Russia, Nikonov readings, 14 35-37 (2009)

17. V.D. Goncharov, S.V.Koteev, Ye.N.Yakubovich, Food Complex of the Russian Federation (Moscow, INEC, 2013)

18. V.V. Orlov, Yu.V. Klokov, Food industry 8, 20-21 (2000)

19. E.Yu. Pravovednikova, Izvestia of the Regional Financial and Economic Institute. Electronic scientific journal 1, 57-64 (2013)

20. A. Privalov, Expert 40, 3-9 (2016)

21. D.A. Loginov, E.V. Karanina, A.A. Bakhtimov, O.A. Ryazanova, Contributions to economics 9783319606958, 69-76 (2017)

22. D. Loginov, V. Stepanyan, Engineering for Rural Development Proceedings, 1140$1146(2018)$ 